\title{
Key factors strengthening the resilience of social logistics systems
}

\author{
Mateusz Zaczyk \\ Silesian University of Technology / Institute of Management, Administration and Logistics
}

\begin{abstract}
The article presents basic assumptions defining the resilience of logistics systems focused on satisfying societies' needs. The author emphasized the importance of systems theory for the contemporary understanding of management science. The article describes the concept of social logistics as one of three basic types of logistics. The importance of identifying social needs for understanding the essence of social logistics was highlighted. The article contains a proposition of a set of elements being part of the social logistics system and the characteristics of connections between them. In addition, a composition of factors increasing the sensitivity of social logistics systems and a set of measures to strengthen the resilience of the systems in question were proposed. The second part of the article presents the results of empirical research in the field of key factors strengthening social logistics systems' resilience, which were carried out among representatives of secondary and higher schools from highly industrialized region of southern Poland. The article is another link in the series of publications on shaping the resilience of social logistics systems. Within its framework, pilot studies of both qualitative and quantitative nature were carried out leading to the compilation of a set of the most important points of sensitivity of social logistics systems and factors that could strengthen their resilience from the point of view of representatives of southern Poland's society. The factors that strengthen the resilience of social logistics systems identified in their framework have been subjected to the further research procedure described in this article.
\end{abstract}

Keywords: polish society; social responsibility; society needs; systems' theory; vulnerability. 